\title{
Identidade, Drogas e Saúde Mental: Narrativas de Pessoas em Situação de Rua
}

\author{
Jéssica Silva Rodrigues \\ Aluísio Ferreira de Lima \\ Universidade Federal do Ceará, CE, Brasil. \\ Universidade Federal do Ceará, CE, Brasil. \\ Renata Bessa Holanda \\ Universidade Federal do Ceará, CE, Brasil.
}

\begin{abstract}
Resumo: O presente trabalho tem por objetivo discutir como pessoas que vivem em situação de rua e que fazem uso abusivo de drogas lidam com os processos de exclusão social aos quais estão submetidos, observando de que forma os personagens que representam repercutem no reconhecimento de suas identidades. Para tanto, seguindo o critério de saturação de sentido, foram utilizadas as narrativas de dois sujeitos que viviam em situação de rua no centro de Fortaleza (CE) e que faziam o uso de drogas. Nas pesquisas desenvolvidas por Antonio da Costa Ciampa e Aluísio Ferreira de Lima, sobretudo aquelas relacionadas à concepção de identidade enquanto metamorfose, personagem e as categorias mesmice, mesmidade e reconhecimento. Assim, no estudo pode-se perceber o impacto das formas de reconhecimento experienciadas pelos sujeitos entrevistados na constituição de suas identidades, bem como as repercussões dos estigmas enfrentados pelos mesmos na representação cotidiana das personagens "pessoa em situação de rua" e "usuário de drogas". Por fim, as rupturas dos personagens nos processos de mesmice e a dificuldade de lidar com novos personagens nos movimentos da mesmidade são discutidas, além de reflexões sobre as identidades pressupostas atribuídas a essas duas personagens, que criam limitações nas relações dessas pessoas com os trabalhadores dos serviços de saúde mental e acabam reproduzindo as formas de exclusão vivenciadas por eles.
\end{abstract}

Palavras-chave: Psicologia Social, Identidade, Uso de Drogas, Pessoas em Situação de Rua, Saúde Mental.

\section{Identity, Drugs and Mental Health: Narratives of People Living on Streets}

\begin{abstract}
The purpose of this study is to discuss how people who live on streets and are drug users, deal with the social exclusion they are subjected to, observing how the characters they represent influence their identities. Therefore, following the criterion of saturation, the narratives of two persons who lived on streets in the center of Fortaleza (CE) and who are drug users were utilized. Propositions presented by Antonio da Costa Ciampa and Aluísio Ferreira de Lima, particularly those for narratives analysis, particularly those related to the conception of identity as metamorphosis, and character, sameness, personhood and recognition categories. Thus, in the study we can perceive the impact of the forms of recognition experienced by the subjects interviewed in the constitution of their identities, as well as the repercussions of the stigmas faced by them in the everyday representation of the characters "person living on streets" and "drug user". Finally, the ruptures of the characters in the processes of sameness and the difficulty on dealing with new characters in the movements of personhood are discussed. Reflections about how the assumed identity attributed to these two characters creates limitations on the interactions of these people in their relations with employees of mental health services, who end up reproducing the forms of exclusion experienced by them, are also analyzed.
\end{abstract}

Keywords: Social Psychology, Identity, Drug Use, Person Living on Streets, Mental Health. 


\title{
Identidad, Drogas y Salud Mental: Narrativas de Personas que viven en Situación de Calle
}

\begin{abstract}
Resumen: El presente trabajo tiene por objetivo discutir cómo las personas que viven en situación de calle y que hacen uso abusivo de drogas tratan con los procesos de exclusión social a los que están sometidos, observando de qué forma los personajes que representan repercuten en el reconocimiento de sus identidades. Para ello, siguiendo el criterio de saturación de sentido, fueron utilizadas las narrativas de dos sujetos que vivían en situación de calle en el centro de Fortaleza (CE) y que hacían el uso de drogas. En el análisis de estas narrativas se utilizaron las proposiciones presentadas por proposiciones presentadas por Antonio da Costa Ciampa y Aluísio Ferreira de Lima sobre todo aquellas relacionadas con la concepción de identidad como metamorfosis, personaje y las categorías marasmo, aburrimiento y reconocimiento. Así, en el estudio se puede percibir el impacto de las formas de reconocimiento experimentadas por los sujetos entrevistados en la constitución de sus identidades, así como las repercusiones de los estigmas enfrentados por los mismos en la representación cotidiana de los personajes "persona en situación de calle" y "usuario de drogas". Finalmente, se discuten las rupturas de los personajes en los procesos de marasmo y la dificultad de tratar con nuevos personajes en los movimientos de rutina, además de las reflexiones sobre cómo la identidad atribuida a esas personificaciones, crean limitaciones en las interacciones de esas personas en sus relaciones con los trabajadores de los servicios de salud mental, que acaban reproduciendo las formas de exclusión vividas por los mismos. Por fin, se discuten las rupturas de los personajes en los procesos de mismísima y la dificultad de lidiar con nuevos personajes en los movimientos de la miseria, además de reflexiones sobre las identidades supuestamente atribuidas a esos dos personajes, que crean limitaciones en las relaciones de esas personas con los trabajadores de los servicios de salud mental y acaban reproduciendo las formas de exclusión vividas por los mismos.
\end{abstract}

Palabras clave: Psicología Social, Identidad, Uso de Drogas, Personas en Situación de Calle, Salud Mental.

\section{Introdução}

O presente artigo, resultante de um Trabalho de Conclusão de Residência Multiprofissional em Saúde Mental - TCR (Rodrigues, 2017), surgiu, enquanto tema de pesquisa, durante a experiência prática da primeira autora como psicóloga residente na Escola de Saúde Pública do Ceará, no projeto intitulado "Residência na Rua: Saúde, Arte e Cultura", realizado em parceria com a Secretaria de Cultura do Ceará (SECULT-CE). O projeto em questão originou-se da iniciativa de seis residentes que estavam interessados no desenvolvimento de ações de promoção de saúde mental, utilizando a arte e a cultura como estratégias de redução de danos, com a população que vive em situação de rua nos entornos de uma praça da capital cearense. Tais ações foram realizadas com frequência semanal (mais especificamente, três vezes por semana) durante seis meses ininterruptos. Dentre elas: a) ações de promoção de saúde, b) distribuição de insumos, c) abordagens de rua, d) realização de atividades musicais, corporais, artísticas e lúdicas, além de e) articulação e acompanhamento de casos na rede intersetorial.

No TCR procurou-se discutir como se dão os processos de metamorfose da identidade de pessoas que vivem em situação de rua na cidade de Fortaleza (Ceará) e que fazem uso abusivo de drogas. Especificamente, procurou-se compreender como essas pessoas que representam em seu cotidiano as personagens "pessoa em situação de rua" e "usuário de drogas" estão submetidas aos processos de exclusão social, observando de que forma estes repercutem no reconhecimento de si mesmos e no reconhecimento das pessoas que se relacionam.

Sabemos que utilizamos o termo "população em situação de rua" para nos referir às pessoas que, por 
motivos diversos, passaram a habitar logradouros públicos das cidades, fazendo destes o seu espaço de convivência e realização de atividades diárias e individuais. As populações que vivem em situação de rua também enfrentam diversos estigmas e representações sociais depreciativas, que podem estar relacionadas ao fato de essas pessoas residirem nas ruas, viverem em precárias condições de higiene e, em alguns casos, sofrerem de incapacidade física ou mental, com baixo nível de escolaridade e renda mensal abaixo de um salário mínimo (Barata, Carneiro Junior, Ribeiro, \& Silveira, 2015). Pinheiro e Monteiro (2016) citam algumas representações associadas, frequentemente às pessoas em situação de rua, como a rotulação enquanto vítima ou ameaça social, loucos, sujos ou perigosos.

Segundo estudo realizado pelo Ministério do Desenvolvimento Social e Combate à Fome (Brasil, 2009), o uso de drogas se encontra entre os principais motivos que levam as pessoas a viverem em situação de rua, uma vez que $35,5 \%$ das pessoas alegaram estar nesta situação devido ao uso de álcool e/ ou outras drogas. Dentre as possíveis aproximações entre esses dois grupos populacionais (pessoas que vivem em situação de rua e pessoas que fazem uso de drogas), Macerata (2014, p. 166) destaca que recai sobre ambos os grupos a qualificação de "populações vulneráveis", assim como forte estigmatização. Ambos "sofrem exclusões concretas e contínuas na dinâmica social e na saúde pública" (Macerata, 2014, p. 166). Contudo, o mesmo autor ainda expande a discussão sobre tais grupos, quando afirma que é válido ressaltar que "nem toda pessoa que vive na rua usa drogas e nem todo usuário abusivo de drogas vive na rua. $\mathrm{O}$ uso de drogas permeia todo o tecido social" (Macerata, 2014, p. 165).

Entretanto, dado às vulnerabilidades socioeconômicas às quais estão expostas as pessoas que vivem nas ruas e que fazem uso abusivo de drogas, estas se tornam mais vulneráveis aos controles, repressões e exclusões baseados em estigmas e estereótipos que associam a figura do morador de rua usuário de droga ao estereótipo de bandido ou criminoso, aquele que representa perigo à sociedade. Dessa maneira, percebemos que "O estigma, o estereótipo construído em torno de pessoas que vivem nas ruas e fazem uso de drogas ilícitas, é concomitante a uma espécie de julgamento moral sobre seus modos de viver" (Macerata, 2014, p. 167).
Isso não é nenhuma novidade, pois de maneira geral, no Brasil, o uso de drogas é frequentemente associado às questões judiciais e policiais, fato que acarreta a criminalização não apenas do consumo das substâncias ilícitas, mas também das pessoas que as utilizam, reflexo da política de guerra às drogas adotada pelo Estado (Lancetti, 2015; Prestes, 2017). A criminalização e proibição corrobora para o processo de estigmatização das pessoas que usam drogas ilícitas, uma vez que, ao fazerem o uso, são associadas ao estereótipo de criminosos e sujeitos perigosos. Além disso, a proibição de certos tipos de drogas não elimina os consumos, mas, sim, acaba por gerar efeitos sociais que transformam seus sentidos, como por exemplo, a demonização (uma proibição que cria pânico moral e estigmas) e a glamorização (que confere às drogas uma aura transgressiva) (Mayora, 2016).

Desse modo, essas pessoas passam a ter suas vozes silenciadas e seus direitos desrespeitados, como nos mostra Vedovatto (2010, p. 164):

[...] vimos que a pessoa que usa drogas não tem vez nem voz, porque na formulação de Políticas Públicas voltadas à questão de drogas são chamados diversos atores sociais envolvidos na questão DROGAS: policiais, juristas, políticos, padres, pastores, médicos, psicólogos, sociólogos, dirigentes de comunidades terapêuticas, representantes de associações médicas, Ministério da Saúde, Secretaria Nacional de Políticas de Drogas, mas não são chamados representantes do público-alvo, ou seja, nunca são consultadas pessoas que fazem uso de drogas para discutir qual a melhor forma de se pensar em políticas públicas que contemplem suas necessidades.

Portanto, constantemente lhes são negados direitos à participação social, autonomia e possibilidades de vivenciarem e se reconhecerem em outros personagens que não apenas ao do usuário de drogas. Além disso, essas pessoas são, frequentemente, associadas às questões de violência, crime e demais valorações pejorativas.

No estudo realizado com pessoas em situação de rua na cidade de São Paulo, aponta-se que um terço dessa população se sentia discriminada ao frequentar os serviços de atenção à saúde e $55 \%$ revelou considerar sua situação de saúde regular, ruim ou muito ruim (Barata et al., 2015). A referida pesquisa destacou, 
ainda, alto índice de sentimento de discriminação associado à condição de morador de rua na cidade. Em outra pesquisa, Prates, Prates e Machado (2011, p.197) também foi identificado esse sentimento de discriminação experienciado por pessoas em situação de rua, no caso, aquilo que denominaram como sendo um processo de autoexclusão, a partir do "não reconhecimento de si próprios como sujeitos de direitos, como parte integrante da sociedade", tendo em vista a constante violação de seus direitos e a discriminação social relacionadas às precárias condições de vida em que se encontram.

O sentimento de discriminação tem relação direta com as formas de reconhecimento e é resultado das "políticas de identidade" direcionadas à "população em situação de rua" e aos "usuários de drogas". Isso porque, na medida em que as políticas de identidade apresentam scripts a serem seguidos e que discriminam quem são e como devem agir determinados sujeitos, acabam por produzir personagens que podem ser vivenciados por essas pessoas como a única possibilidade de ser reconhecido e de estar no mundo que os cerca. Problema que aparece como de extrema relevância para a pesquisa, uma vez que partimos de articulações que revelam uma possível construção socialmente realizada desses predicados, que se materializam como identidades pressupostas estigmatizantes atribuídas às pessoas em situação de rua que fazem uso de drogas, tidas como sujeitos outsiders problemáticos, perigosos e/ou doentes (Becker, 2008; Goffman, 1980).

Além disso, no que se refere à possibilidade de acesso às políticas públicas de saúde mental e assistência social, as políticas de identidade direcionadas às pessoas que estão em situação de rua dificultam o reconhecimento desses sujeitos enquanto portadores de direitos. Não por acaso é possível presenciar com frequência profissionais reproduzindo estigmas em relação a esses sujeitos, ao embasarem suas práticas em comportamentos moralistas de cunho normativo e patologizante, que mais contribuem para aprisionar essas pessoas às identidades pressupostas fetichizadas do que para propiciar a exploração de novas possibilidades de ser e estar no mundo. Lima (2010) descreveu esse processo como "reconhecimento perverso", que se refere à forma de reconhecimento direcionada para as pessoas que não considera suas várias possibilidades de existência, as várias representações de personagens que vivem, reduzindo essas diversas personagens a uma única, como se fosse a "identidade" dos sujeitos que buscam reconhecimento. A expressão daquilo que Agamben $(2014$, p. 82) denominou como "identidade sem pessoa", em que o código oriundo de um manual passa a ser o referencial para as interações interpessoais, "sem o peso das implicações afetivas que são inseparáveis do reconhecimento operado por outro ser humano".

No que se refere à questão identitária, Ciampa (1987) oferece uma importante contribuição. Este autor propõe que qualquer tentativa de compreensão do sujeito deve partir da proposição de que a identidade é metamorfose, ou seja, o que caracteriza a identidade são as mudanças e o constante devir que constitui cada um dos sujeitos, rompendo assim com uma concepção antes considerada como estática. Nas palavras desse autor: "a identidade é, sobretudo, uma questão social, uma questão política” (Ciampa, 1987, p.133).

Ciampa (1987) ainda apresenta mais duas categorias que corroboram na análise da identidade como metamorfose: a "mesmice" e a "mesmidade". A primeira, "mesmice" (que se refere a um idem) permite analisar os processos onde aparentemente os sujeitos estão "cristalizados", impedidos de novas atualizações e projetos de si mesmos, na qual permanecem repondo os papéis que lhe são atribuídos, a partir do reconhecimento que lhe é dado pelo outro. Ou seja, o sujeito pode manter uma constante reposição do mesmo personagem frente às diversas situações vivenciadas, dando uma aparência de não metamorfose. A segunda ajuda na apreensão das possibilidades de emancipação encontradas por esses sujeitos em seus contextos, nas transformações daquilo que aparentemente está naturalizado em sua percepção de si. Nesse caso, ao se descobrirem representantes não apenas de um personagem, mas de vários, vivem o que Ciampa denominou como processo de "mesmidade" (que se refere a um ipse), um salto qualitativo neste processo de percepção de si.

Assim, considerando as questões acima expostas, nesse artigo discutiremos os achados das narrativas de pessoas que vivem em situação de rua na cidade de Fortaleza e que fazem uso abusivo de drogas, de modo a evidenciar a inter-relação entre os estigmas socialmente construídos e o modo como esses sujeitos se percebem e falam sobre si mesmos, buscando compreender, a partir de suas narrativas, os processos de construção de suas identidades. De modo esquemá- 
tico, apresentaremos os caminhos seguidos (método) que levaram à escolha da narrativa de história de vida de José e Pedro (nomes fictícios). A seguir, apresentaremos os participantes e discutiremos cada uma das narrativas, onde será possível vislumbrar o impacto das formas de reconhecimento experienciadas por cada um dos entrevistados e os efeitos na constituição de suas identidades. O trajeto levará à discussão acerca das repercussões dos estigmas enfrentados pelos mesmos na representação cotidiana das personagens "pessoa em situação de rua" e "usuário de drogas".

\section{Metodologia}

Para alcançar os objetivos da pesquisa, partiu-se da metodologia utilizada por Ciampa (1987) e desenvolvida por Lima $(2010 ; 2014)$, que prioriza as narrativas dos sujeitos sobre suas histórias de vida, tomando como foco de análise a narração e o sentido aos fatos que perpassam suas vidas, aos eventos que contribuíram para a construção de si mesmos. As "narrativas de história de vida" (Lima, 2014) se caracterizam por serem uma forma de entrevista não-estruturada cujo objetivo é analisar em profundidade os fatos narrados pelos sujeitos pesquisados. O pesquisador, nessa perspectiva, assume um lugar de testemunha, de forma a registrar os fatos marcantes narrados pelos sujeitos. É relevante destacar que esse método permite que os entrevistados assumam o papel de narrador, função essa que muitas vezes lhes é negada socialmente.

A adoção desse tipo de entrevista se justifica por permitir abordar, de modo privilegiado, o universo subjetivo do(a) entrevistado(a), assim como todas as questões e acontecimentos que fazem parte de sua história. Afinal, a narrativa de uma história de vida evidencia uma sucessão de contextos e de personagens, onde o que é relatado não só afeta os próprios contextos, como também transformam os próprios narradores (Bertaux, 2005). Ao contar-se, o participante apresenta performaticamente sua identidade, reconstruindo seu passado, revelando conflitos, rupturas e pactos que fez com outros sujeitos e consigo mesmo.

No momento da narrativa, emergem conteúdos relativos às experiências dos sujeitos no presente $\mathrm{e}$ no passado, assim como suas expectativas de futuro, ocorrendo, portanto, uma inter-relação entre presente, passado e futuro dos sujeitos entrevistados. Dessa forma, pode-se afirmar que "o recurso da narrativa coincide com a perspectiva de movimento, no sentido teórico, pois através dela é possível conseguir novas variáveis, questões e processos que podem conduzir a uma nova orientação da área em estudo" (Muyalaert, Sarubbi Júnior, Gallo, Rolim Neto, \& Reis, 2014, p. 195).

O critério utilizado para seleção dos participantes e a escolha da área central de Fortaleza como lócus da pesquisa se deram pelos dados apresentados no censo divulgado em junho de 2015 e realizado pela Secretaria Municipal de Trabalho, Desenvolvimento Social e Combate à Fome (Setra) da cidade de Fortaleza (CE), segundo o qual o centro da cidade é a região em que existe maior concentração de pessoas em situação de rua. Além desses critérios, foram consideradas a disponibilidade e interesse dessas pessoas em participar desse estudo, com idades superiores a 18 anos, com vivência em situação de rua, que faziam uso de drogas e tinham acesso aos serviços de saúde mental.

No que se refere à quantidade de participantes, utilizou-se a saturação de sentido como critério para a quantidade de narrativas a serem registradas. Ou seja, os convites aos participantes foram encerrados no momento em que foi percebido a presença de uma certa "repetição" de determinados conteúdos e uma certa homogeneidade nas narrativas apresentadas (Fontanella, Ricas, \& Turato, 2008; Lima, 2014). O critério adotado resultou na escolha de dois participantes que estavam em situação de rua em Fortaleza, faziam uso de drogas e tinham acesso aos serviços de saúde mental, do sexo masculino, com idades de 31 e 43 anos, selecionados por conveniência, considerando a aproximação progressiva da pesquisadora com cada um dos participantes, a partir de conversas informais advindas da aproximação sistemática por meio de abordagem de rua no centro da cidade, mediante participação no projeto Residência na Rua: Saúde, Arte e Cultura", realizado em parceria com a Secretaria de Cultura do Ceará (SECULT-CE), em 2016.

Os nomes fictícios José e Pedro, escolhidos pelos participantes, foram aceitos e utilizados de modo a representar diversos brasileiros, dado o fato de serem nomes comuns, que constituem a identificação social de muitos brasileiros. Suas narrativas foram gravadas e analisadas, de modo a intentar uma aproximação com as vivências dos entrevistados relacionadas aos processos de exclusão social aos quais estiveram expostos ao longo de suas vidas, incluindo as questões relacionadas ao fato de estarem em situação de rua e fazerem uso de drogas. Faz-se importante assinalar 
que a presente pesquisa foi realizada mediante aprovação no comitê de ética da Escola de Saúde Pública do Ceará ( $\mathrm{n}^{\circ}$ 1.735.129). Foram obtidos, também, os consentimentos da exposição dos conteúdos apresentados, sendo registrados nos Termos de Consentimento Livre e Esclarecido (TCLE) assinados pelos participantes e que seguiu todas as orientações e exigências da Resolução n ${ }^{0}$ 510/2016 do Conselho Nacional de Saúde.

A análise e interpretação das narrativas foram realizadas considerando-se os aspectos históricos, sociais e culturais na constituição dos sujeitos participantes da pesquisa, assim como os aspectos teóricos relativos à construção da identidade dos mesmos e condições de reconhecimento aos quais estão/estiveram subordinados em suas vidas. Como se sabe, uma narrativa de história de vida não é uma sequência lógica (uniforme) de eventos, mas uma constelação, onde os acontecimentos mais significativos tomam cena e podem confirmar as trajetórias ou contribuir para defini-las. Trata-se de um conjunto de instantes rememorados, fragmentos de vida, que expressam a identidade (Ciampa, 1987; Lima, 2010; 2014). Nesse sentido, nas análises das narrativas de história de vida procurou-se identificar os personagens experienciados pelos indivíduos, de modo a (re)construir cada trajetória individual.

\section{Sobre os achados da pesquisa: as narrativas de história de vida de José e Pedro}

José tem 43 anos, nasceu no estado do Maranhão e mudou-se para Fortaleza por motivo de trabalho. Casou-se aos 21 anos e desde então foi morar na casa da família de sua companheira. Após conflitos com os familiares de sua esposa, passou a viver numa praça no centro da cidade, por escolha sua, por considerar-se "opinioso" e não se sentir confortável ao precisar de "ajuda" de outras pessoas. Assim sendo, optou por não procurar seus pais e irmãos, que, segundo ele, poderiam ajudá-lo.

Com isso, há aproximadamente 18 anos vive em situação de rua em Fortaleza. Ao longo dos anos nessa situação, José afirma ter se "acomodado" a ela, passando a fazer uso cada vez mais frequente do álcool e do cigarro. Segundo ele, escolheu não fazer uso de outras substâncias (a seu ver mais "pesadas" como crack, por exemplo) por acreditar que poderia manter maior controle sobre o uso de drogas como álcool e cigarro, já usadas por ele antes de viver em situação de rua. José se reconhece enquanto alguém, na praça, que procura ajudar aos seus companheiros, orientando-os a "não se envolver com coisas erradas", que, para ele, seriam assaltos e uso abusivo de substâncias ilícitas.

José afirma ter cinco profissões (dentre elas eletricista e pedreiro) e trabalhar em empregos informais e sazonais. No momento da entrevista, acabara de conseguir um "bico", após meses sem obter recolocação no mercado de trabalho. Segundo ele, após estar em situação de rua, as possibilidades de emprego tornaram-se mais escassas. No período de realização da entrevista, José estava passando por um momento de transição em sua vida, haja vista a volta para casa e a conquista de um novo emprego nos arredores da praça. Após insistência de sua companheira na procura por José, ele decidiu retornar à casa havia um mês, entretanto, continuava passando seus dias na praça, pois, segundo ele, é lá que estão seus amigos e suas possibilidades de conseguir emprego.

Pedro, por sua vez, tem 31 anos, é solteiro, nasceu no estado de Pernambuco, vive em Fortaleza há aproximadamente 7 anos e, atualmente, está em situação de rua. Relata que perdeu sua mãe quando tinha três anos de idade e que foi criado por uma madrasta da qual não recebera muito afeto. Segundo ele, a madrasta devotava amor e carinho às suas duas irmãs, filhas biológicas de sua madrasta, com idades próximas à dele, rejeitando-o. Essa rejeição o marcou, apesar do afeto recebido por parte do pai e das irmãs, como nota-se em sua narrativa.

Aos 23 anos, Pedro iniciou o uso de drogas, experimentando cocaína em festas, ao sair com amigos, no intuito de se sentir mais feliz e sentir algo novo. Após a família reconhecer o seu uso enquanto problema, sugeriram que ele se internasse em uma comunidade terapêutica, a fim de parar de usar drogas. Pedro aceitou o encaminhamento e, dessa forma, veio para sua primeira internação em uma comunidade terapêutica que se localiza em Fortaleza, na qual passou 8 meses. Após esse período, iniciou um relacionamento amoroso, começou a trabalhar e decidiu morar na capital cearense.

Passados alguns meses voltou a usar drogas, tendo passado, até o momento da entrevista, por 17 internações em comunidades terapêuticas. Terminou um relacionamento amoroso, perdeu e ingressou em diversos empregos nos últimos anos, até que 
não conseguiu nova recolocação profissional e passou a viver em situação de rua numa praça no centro da cidade. Atualmente, Pedro faz uso constante de crack e optou por nova internação em comunidade terapêutica semanas após a entrevista realizada para essa pesquisa.

\section{Discussão: sobre aquilo que as narrativas de José e Pedro ensinam}

Ciampa (1987, p. 141), conforme assinalado anteriormente, propõe que a identidade é metamorfose. Nessa perspectiva, a representação de si ao longo de uma vida se dá pela criação e representação de personagens que, por sua vez, são exercidas por suas atividades; dessa forma, propõe-se que o indivíduo seja compreendido enquanto relação, algo que está se dando, numa ideia de processo, e não que está dado, encerrado. O referido autor destaca ainda a importância do reconhecimento do outro e do contexto social em que os sujeitos estão inseridos no processo de constituição da identidade e do reconhecimento de si.

Em sua narrativa, José destaca dois personagens em que se reconhece: o José-rei, referindo-se ao momento em que vivia em casa, com sua família, ambiente em que se sentia respeitado e amado; e o José-lixo, referindo-se ao período em que viveu nas ruas, momento este em que passou por diversas privações, como precária higiene pessoal, frio e medo da violência na rua. Nesse ponto, faz-se importante destacar os processos de metamorfose vividos por José, refletidos nas diferentes percepções de si. Enquanto José-rei, apesar de viver alguns conflitos com familiares de sua esposa, ele se percebia enquanto sujeito merecedor de respeito e afeto. Ao passar a viver nas ruas, vivenciou tratamentos e reconhecimentos sociais distintos, sendo encarado como morador de rua, representando o José-lixo, a quem era negado seus direitos. Passou a ser sujeito de olhares de "desconfianças" e "suspeitas" por parte da sociedade, constantemente associado ao estereótipo do "morador de rua".

A narrativa de Pedro, por sua vez, apresenta dois momentos assinalados como muito importantes na sua vida, onde o uso de drogas aparece como elemento que marca a passagem de um momento para o outro. Para ele,

[...] antes de eu conhecer a droga, eu vivia mais dentro de casa, mais perto das minhas irmãs, perto da minha família. Mas depois que eu me envolvi com a bebida, com farra, com as drogas, deixei minha família de lado, as pessoas que me amam de lado.

Pedro acredita que após o uso contínuo de drogas, passou a ser "uma pessoa enganadora, falsa, egoísta, que só queria saber de mim, não pensava nas pessoas". Essa forma de reconhecer a si mesmo produz certa insatisfação consigo e, ao mesmo tempo, uma recusa por não ter aceitado a identidade pré-estabelecida por sua família. Em seu relato, define-se como alguém que não soube aproveitar as oportunidades que teve para viver uma vida diferente, e vê-se como alguém capaz de destruir as vidas das pessoas que dele se aproximam:

[...] terminei me tornando uma pessoa agressiva, uma pessoa manipuladora, uma pessoa egoísta, orgulhosa, prepotente [...]. Eu terminei me viciando em droga, eu terminei destruindo a vida de pessoas [...].

Nas narrativas de José e Pedro, evidenciam-se nuanças dos processos de metamorfose de suas identidades, de como se percebem e narram a si mesmos. Destacam-se mais evidentemente, demonstrado inclusive pelo período vivenciado por José, os processos de "mesmice", ao repor o personagem José-lixo durante os anos vividos nas ruas da capital, momentos nos quais não identificava outras possibilidades de ser. Entretanto, ao longo de suas experiências, suas relações com alguns amigos e familiares, José decide voltar à casa, apesar de, aparentemente, os conflitos familiares persistirem. Ao voltar, ele torna a viver o personagem José-rei. O rompimento entre personagens produz modificações do si mesmo e do autorreconhecimento de si, caracterizando episódios de "mesmidade".

Na narrativa de Pedro, a "mesmidade" aparece de modo mais evidente quando narra o rompimento com o personagem Pedro-família, surgindo o personagem Pedro-enganador. A nova personagem, entretanto, não é bem avaliada por Pedro atualmente. Em sua narrativa, o personagem Pedro-família evidencia-se como algo bom, que ele deveria ter seguido, mas não o fez, gerando um processo de culpabilização de si. O personagem Pedro-enganador, que surge a partir de sua relação com as drogas, é significado por ele como algo ruim. 
Não por acaso, Pedro fala de si mesmo enquanto um sujeito dividido e à mercê de duas "forças", uma que o "puxaria" para o lado do bem (relacionado às vivências do personagem Pedro-família) e outra que o "puxaria" para o lado do mal (relacionado às vivências do personagem Pedro-enganador), colocando-o em conflito permanente. Dessa tensão surge a personagem que representa atualmente: Pedro-que-precisa-de-ajuda. Esse personagem, entretanto, que poderia gerar a criação de novas personagens que escapassem do conflito entre o Pedro-família o o Pedro-enganador, ainda não é capaz de produzir potência suficiente. Pedro ainda se sente preso à espiral uso abusivo de drogas-internação-diminuição do uso-rua-uso abusivo de drogas ao longo dos últimos anos. Como é possível observar, na narrativa de Pedro, a droga se apresenta como elemento central, sendo o marcador principal entre os momentos vividos citados na entrevista, uma espécie de "divisor de águas" em sua trajetória de vida, aquilo que o leva à condição de "pessoa em situação de rua".

Na narrativa de José, por outro lado, a experiência de viver nas ruas aparece como elemento central para a manutenção do uso de drogas, sobretudo porque o uso de drogas é narrado por ele como um dos elementos importantes em seu contexto de vida, usada, sobretudo, como o apoio que não encontra em outros lugares.

[...] ajuda e não ajuda, porque tá prejudicando a minha saúde, mas eu me acalmo, eu me controlo, até pra fazer essa entrevista aqui, você viu que eu pedi pra ir comprar cigarro, que era pra eu me concentrar e falar, me acalma, o álcool também é a mesma coisa, bebo pra relaxar. [...] sem o álcool não teria como ter conseguido passar pelo que passei aqui, porque aqui, você tem que se ocupar em alguma coisa ou trabalhar ou beber, mesmo numa situação de frio, o álcool me esquentava, o álcool era a única companheira.

Diferentemente de Pedro, o uso de álcool não é compreendido por José como uso de drogas e afirma que tal uso é, para ele, algo controlável, uma vez que, ao sentir que havia atingido um limite, interrompia o uso para que não perdesse o controle. Em suas próprias palavras:

[...] não me considero um aviciado, só é aviciado quando a pessoa quer, a pessoa só vai roubar, só vai brigar, quando os dois querem brigar [...].
Eu controlo o álcool, porque quando eu não tô a fim de beber eu não bebo, bebo no dia que tenho mais raiva.

Nas duas narrativas, entretanto, é possível perceber o lugar ocupado pelas drogas nas vidas de José e Pedro. As narrativas corroboram com os achados de Moura Júnior e Ximenes (2016), que apontam que o uso da droga pode ocupar o papel de substituto dos afetos e das relações, uma vez que "fornece novas formas de mediação do sofrimento e do incômodo" (Moura Júnior, \& Ximenes, 2016, p. 266). Isso se torna mais evidente na fala de Pedro quando afirma que "usar droga começou através de uma necessidade de eu querer me tornar e ser mais feliz"; e de José quando afirma que, ao passar a viver nas ruas, momento em que vivenciou o personagem lixo, aumentou o uso de álcool e cigarro: "Quando eu cheguei aqui na Praça, foi quando eu fiquei, vamos dizer assim, mais dependente dela [...]. Todo dia, bebia até o meu limite".

As diferentes nuanças frente aos sentidos atribuídos aos usos de drogas pelos participantes em suas narrativas são importantes porque permitem observar aquilo que Bergeron (2012) assinalou acerca dos estigmas vivenciados por pessoas que fazem uso de álcool e de crack, no caso, que as experiências de preconceito se dão de formas diferentes, algo que pode ser relacionado ao fato de o primeiro ser lícito e o segundo não. Em geral, o álcool não é compreendido como droga, desconsiderando-se os males causados à saúde das pessoas que fazem uso dessa substância. Isto está presente nas entrevistas, quando José afirma que álcool e tabaco não são drogas e ao se reconhecer como diferente de outras pessoas que ali vivem, por não fazer uso de drogas, como no seguinte trecho:

[...] me sentia abatido, fraco, em tempo de cair nas drogas, a única droga que eu achei fácil pra mim, que eu sabia que eu controlava ela, que eu controlo, é a cachaça e eu penso assim, se eu fosse usar o crack, o pó, a maconha, eu acho que ia ficar dependente à ela, eu ia ficar acabado, relaxado, como muitos amigos meus que vivem aqui em situação de rua que relaxam, que fica relaxado, anda sujo, com cabelo grande, com mal cheiro, sem tomar um banho.

Nesse trecho, nota-se o reconhecimento de si enquanto diferente dos colegas que fazem uso mais 
abusivo de substâncias e, principalmente, das ilegais. Além disso, torna-se evidente a associação entre aqueles que fazem uso destas últimas com os estados de maior ausência de cuidado de si, seguindo o estereótipo do "drogado".

Na contramão do discurso de controle do uso apresentado por José, encontramos na narrativa de Pedro a ideia de que é incapaz perante as substâncias que utiliza, uma vez que compreende a droga como algo capaz de retirar o prazer que ele sentia ao exercer outras atividades:

[...] uma pessoa que se envolveu com droga, ela perdeu o valor e o gosto dessa dormida dentro de casa. Teve muitas coisas que foram perdidas, teve outras coisas, a convivência com a família, andar de bicicleta, se deleitar lendo um livro, ter prazer em simplesmente, só de tá perto da família, prazer de sair pra uma praia, prum restaurante, de brincar com a família, né? São coisas mínimas que a droga tira de uma pessoa sem que ela perceba. Eram coisas que me faziam bem, mas simplesmente por causa do uso da droga esse prazer por essas coisas foi perdido, entende?

No caso de Pedro, percebe-se "um processo de subjetivação desenvolvido por uma ordem capitalista de anulação do sujeito e personificação da droga como capturando o indivíduo" (Moura Júnior, \& Ximenes, 2016, p. 267). Ou seja, a droga assumindo um papel personificado que tem o poder ativo de retirar os prazeres da vida do sujeito, o qual se torna passivo nesse processo.

Pedro retoma em sua narrativa o falecimento da mãe e a indiferença com a qual era tratado pela madrasta, considerando esses episódios responsáveis pelo seu uso abusivo de drogas:

[Uma sensação de que] teja me escondendo, de querer aceitar quem eu sou de verdade. Não sei se é vergonha, se é por causa de coisas que aconteceram na minha infância e na minha adolescência, né? Algumas coisas que venham fazer a construção do meu caráter [...]. Tenho certeza que se minha criação tivesse sido totalmente diferente eu poderia ser outra pessoa, poderia ter escolhido outro caminho.

Denota-se também, nas narrativas de José e Pedro, que a condição de viver nas ruas aparece como uma experiência marcante que, uma vez que estão submetidos às políticas de identidade que construíram o estereótipo do "morador de rua" e "pessoa em situação de rua", levou os dois a viverem conflitos identitários e, de certo modo, a absorver os estigmas relacionados a essas identidades pressupostas. Não por acaso, José demonstra certa confusão em relação ao se reconhecer como "pessoa em situação de rua”, embora se identifique com essa personagem em alguns momentos: “[...] ainda não me considero um ex-morador de rua, eu ainda sou morador de rua, enquanto eu não me firmar com minha esposa e meus filhos eu ainda sou morador de rua"; e em outras negando-o: “'Tô' aqui vivendo essa vida de situação de rua, mas não me torno um morador de rua”.

Vê-se, ainda, na narrativa o impacto da experiência do estar em situação de rua para a percepção do si mesmo: “[...] eu vivi aquela vida, eu senti na pele, eu passei fome, teve dia que eu passei de 15 dias sem tomar banho. Me via como um lixo, torno em dizer, em bater na mesma tecla, um lixo. Morador de rua é desprezado [...]"(...). ([José).]

Torna-se evidente, ainda na narrativa de José, a negação em se reconhecer na personagem José-em situação de rua, uma vez que essa personagem se relaciona diretamente com uma política de identidade que (re)produz estereótipos e estigmas que se manifestam no reconhecimento do morador de rua como perigoso, violento, drogado etc. Para José é importante frisar que "nem todos que vivem aqui, vivem essa vida", sendo que o emprego aparece na sua narração como elemento de diferenciação entre ele e outros colegas que vivem nas ruas, assim como de negação do estigma do morador de rua, geralmente associado à vida vadia.

Ele, portanto, reconhece-se como José-trabalhador, mesmo que não tenha trabalho ou esteja trabalhando, fala de si como alguém que sempre valorizou o trabalho e buscou emprego, e que não gostava de "se meter com coisa errada" e nem de usar drogas. Na representação da personagem José-trabalhador, o narrador se descreve como alguém que dá conselhos aos outros, que se disponibiliza a ensinar sua profissão aos mais jovens, para que eles também procurem emprego. Nesse ponto, torna-se evidente a centralidade do trabalho e a importância do exercício dessa personagem na vida das pessoas em situação de rua, algo pontuado por Prates, Prates e Machado (2011, p. 65) em outra pesquisa: 
O trabalho, na expressão de um dos entrevistados, é visto como "[...] a primeira porta que se abre" (Brasil, 2008) e que oferece oportunidades para suprir necessidades como alimentos, banho, pousada. Destacam, contudo, que as atividades dirigidas para a capacitação dos sujeitos que antecedem esses processos são de fundamental importância, pois incidem sobre sua autoestima recuperando sua dignidade perdida. Acreditar em si próprios e que é possível ressignificar trajetórias é o primeiro passo para que possam progressivamente superar o processo de rualização, afirmam os sujeitos.

A narração de Pedro segue uma trajetória onde a rua aparece como uma espécie de autopunição, em que ele deve se privar de todas as atividades diárias que lhe davam prazer, assim como da convivência com as pessoas que o faziam sentir-se amado: "Se eu não aprender aqui na rua, em canto nenhum desse planeta eu vou aprender". Estar em condição de rua para Pedro é uma espécie de castigo por ceder às forças que o "puxam" para o lado do "mal", resultado da representação da personagem Pedro-enganador.

No estudo desenvolvido por Moura Júnior, Ximenes e Sarriera (2013, p. 20) com população de rua em Fortaleza (Ceará), observou-se que "o estigma pode acarretar os sentimentos de vergonha e humilhação". Na narrativa de Pedro isso se repete, sobretudo quando se observa que a culpabilização de si mesmo pela sua própria condição, articulada com a fantasia de que se tivesse "se esforçado mais" não passaria pelo que tem experienciado, condena Pedro à reposição dos sentimentos de inferioridade e vergonha por estar vivendo nas ruas.

Talvez tipo de alguma vergonha, né? Por causa da droga, parou no tempo, as pessoas evoluíram e o cara ficou pra trás. Então são questões que faz a pessoa se distanciar. Com certeza [sente que ficou pra trás]. O mundo cada vez mais vai se adiantando e eu, cada vez mais, vou ficando pra trás. Hoje eu tenho amigos que estudaram comigo e são policiais civis, policiais militares, advogados, psiquiatra, psicólogo e eu parei no tempo. Não cursei uma faculdade (Pedro).

Ainda sobre o sentimento de vergonha, os autores citados afirmam que as "práticas discriminató- rias podem fazer as pessoas serem humilhadas e se sentirem envergonhadas, pois igualmente se percebem portando estigmas depreciadores" (Moura Júnior et al., 2013, p. 23), sendo preciso assinalar aqui como essas práticas se expressam nas narrativas dos dois participantes. Quando José narra sobre sua experiência com aos serviços de saúde afirma: "não preciso dos serviços de saúde, não sou doido, não tomo remédio controlado!". A narração reflete a persistência da identidade pressuposta do louco, resultado das políticas de identidade psiquiatrizantes que ainda persistem em nossa sociedade e que ainda produz 0 conjunto de estigmas enfrentados pelas pessoas que frequentam os serviços de saúde mental.

José narra ainda que em momentos onde precisou dos serviços de saúde não se sentiu mal tratado, embora não frequente esses serviços e escute das pessoas que convive muitas críticas em relação aos serviços: "me senti bem tratado quando precisei, mas 'tá' com 4 anos que não vou ao médico, mas vejo a galera falar que é ruim". Ao aprofundar sua análise, José continua

[...] morador de rua é desprezado, órgão público só que ver pelo lado deles, entidade, centro pop, pousada social e outras etecetera que ajuda nós morador de rua, só quer comer dinheiro, nós não ganha nada, só de 15 em 15 dias, 10 em 10 dias, que vai procurar a gente, quando vai fazer a relação pra poder a verba vir, só procura quando é pra arranjar dinheiro, isso eu digo, porque passo e vejo e já senti na pele aqui nessa praça.

A narrativa de Pedro segue a mesma crítica, porém ainda acrescenta um detalhe importante. Quando Pedro narra acerca da demora por atendimento, fá-la afirmando ter sentido diferença no tratamento recebido pelos serviços, diferença essa que, para ele, deve-se ao fato de fazer uso de drogas e não por estar em situação de rua. Nesse ponto, Pedro apresenta a diferença de reconhecimento entre as duas personagens estigmatizantes "usuário de drogas" e "pessoa em situação de rua", que no processo de acolhimento nos serviços de saúde podem resultar em formas distintas de cuidado, dada à ênfase que o profissional dará para cada uma delas. Em alguns casos, a personagem "usuário de drogas" pode chegar a ser reconhecida como "a identidade" do sujeito, impedindo que as demandas relacionadas ao fato de estar em condições de rua sejam atendidas. 
Paiva et al. (2014), em pesquisa realizada com profissionais da saúde, apresentou resultados que mostram a relação existente entre o processo de estigmatização dos usuários de drogas e o distanciamento social dos mesmos. Do mesmo modo, discutiu como o tratamento moral e a culpabilização dos sujeitos reproduzidos por profissionais da saúde frente às pessoas que fazem uso de droga têm produzido o distanciamento e consequente dificuldade de acesso aos serviços por parte dos usuários. Soares et al. (2011) assinalaram, inclusive, a existência de um desejo de distanciamento por parte dos profissionais de saúde em relação às pessoas que fazem uso de drogas:

O desejo de distanciamento muitas vezes acontece a partir da inferência de uma ameaça, ocasionada por percepções distorcidas e compartilhadas das diferenças entre grupos, tais como: características físicas da pessoa rotulada, violações de regras sociais, falta de controle ou imprevisibilidade da doença e responsabilidade atribuída à pessoa pelo surgimento ou solução de sua condição de saúde (Soares et al., 2011, p. 92).

Assim, se por um lado predomina na sociedade "a falta de conhecimento sobre o adoecimento mental, demonstrando que o assunto ainda é pouco discutido com qualidade pela sociedade" (Barros, \& Salles, 2013, p. 1066), por outro lado, os profissionais de saúde têm seguido corroborando com o estigma enfrentado por essas pessoas, levando os profissionais a exercerem práticas autoritárias e estigmatizantes (Soares et al., 2011) e impedindo a construção de ações conjuntas de promoção e prevenção em saúde, principalmente, para a população em situação de rua que sofre duplo processo de exclusão e estigmatização por viverem nas ruas e por fazerem uso abusivo de drogas.

\section{Considerações finais}

A partir das discussões desenvolvidas, pôde-se compreender o impacto das políticas de identidade relacionadas a "pessoa em situação de rua" e "usuário de drogas" nas metamorfoses das identidades das pessoas que cederam suas narrativas. Nas narrativas apresentadas foi possível identificar os momentos de rupturas das personagens que seguiam uma mes- mice e a dificuldade em lidar como as novas personagens surgidas nos movimentos de mesmidade. Foi possível observar saltos qualitativos nas narrativas de José e Pedro. O primeiro rompe com o personagem José-lixo e volta a exercer o papel de José-rei; e o segundo rompe com o personagem Pedro-família e passa a exercer o papel Pedro-enganador, rompendo ainda com este último e passando a representar o personagem Pedro-pessoa-que-necessita-de-ajuda.

Nas duas narrativas ficou evidente o impacto das personagens atribuídas na experiência da rua (pessoa-que-está-em-situação-de-rua e pessoa-que-faz-uso-de-droga) e o desafio que apresentam para a superação da mesmice que passam a viver. No caso de Pedro quando passa a repor continuamente o personagem Pedro-pessoa-que-necessita-de-ajuda, mantendo-se no ciclo uso abusivo-internação-diminuição do uso-rua-uso abusivo, gerando uma aparência de não metamorfose.

As questões relativas aos serviços de saúde, que surgiram de forma secundárias nas narrativas, mais relacionadas às denúncias de fragilidades dos serviços e dificuldades de acesso associadas à reprodução de estigmas por parte dos profissionais das equipes de saúde, apresentam a urgência da reflexão acerca da necessidade de formação dos profissionais de saúde para que, em suas intervenções, considerem os impactos de suas ações nos processos de percepções de si mesmo dos usuários dos serviços de saúde. Além disso, aponta para a necessidade de que se invista em políticas públicas de qualidade que possibilitem às pessoas em situação de rua a exploração de suas potencialidades e proporcionem modos de esses sujeitos se reconhecerem em outros personagens. Tais atividades devem permitir que os sujeitos falem sobre suas trajetórias e se percebam nelas, gerando um processo de reflexão sobre si mesmo e construção de possibilidades de emancipação e metamorfoses frente às situações de opressão vivenciadas pelos mesmos em seus cotidianos.

Finalmente, faz-se importante atentar para o fato de que o presente estudo não se propôs a fazer uma generalização, haja vista que dentro dos pressupostos teóricos da Psicologia Social, utilizados nesse estudo, não há uma proposição de elaboração de verdades ou leis. Pelo contrário, nossa proposta foi analisar os processos de metamorfose da identidade das pessoas entrevistadas, compreendendo as singularidades e limites que cerceiam suas realidades. 


\section{Referências}

Agamben, G. (2014). Identidade sem pessoa. In: g. Agamben, Nudez (pp. 75-86). Belo Horizonte, MG: Autêntica.

Barata, R. B., Carneiro Junior, N., Ribeiro, M. C. S. A., Silveira, C. (2015). Desigualdade social em saúde na população em situação de rua na cidade de São Paulo. Saúdee Sociedade, 24(supl1), 219-232. https://doi.org/10.1590/S0104-12902015S01019

Barros, S., Salles, M. M. (2013). Representações sociais de usuários de um Centro de Atenção Psicossocial e pessoas de sua rede sobre doença mental e inclusão social. Saúde e Sociedade, 22(4), 1059-1071. https://doi. org/10.1590/S0104-12902013000400009

Becker, H. (2008). Outsiders: Estudos de sociologia do desvio (M. L. X. Borges, Trad.). Rio de Janeiro, RJ: Jorge Zahar. Bergeron, H. (2012). A sociologia da droga. Aparecida, SP: Ideias e Letras.

Bertaux, D. (2005). Los relatos de vida: Perspectiva etnosociológica. Barcelona: Edicions Bellatera.

Brasil. (2009). Ministério do Desenvolvimento Social e Combate à Fome. Rua aprendendo a contar: Pesquisa Nacional sobre a População de Rua. Brasília, DF: Ministério do Desenvolvimento Social e Combate à Fome.

Ciampa, A. C. (1987). A estória do Severino e a história da Severina. São Paulo: Brasiliense.

Fontanela, B. J. B., Ricas, J., \&Turato, E. R. (2008). Amostragem por saturação em pesquisas qualitativas em saúde: contribuições teóricas. Cadernos de Saúde Pública, 24(1):17-27. https://doi.org/10.1590/S0102-311X2008000100003

Goffman, E. (1980). Estigma: Notas sobre a manipulação da identidade deteriorada. Rio de Janeiro, RJ: Zahar.

Lancetti, A. (2015). Contrafissura e plasticidade psíquica. São Paulo, SP: Hucitec.

Lima, A. F. (2014). História oral e narrativas de história de vida: A vida dos outros como material de pesquisa. In: A. F. Lima, \& N. Lara Júnior (Orgs), Metodologias de pesquisa em psicologia social crítica (pp. 13-34). Porto Alegre, RS: Sulina.

Lima, A. F. (2010). Metamorfose, anamorfose e reconhecimento perverso: A identidade na perspectiva da psicologia social crítica. São Paulo, SP: Fapesp.

Macerata, I. (2014). Vulnerabilidades do usuário e vulnerabilidades da atenção: Apontamentos iniciais para uma clínica de território na Atenção Básica. In: T. Ramminger, \& M. Silva (Orgs.), Mais substâncias para o trabalho em saúde com usuários de drogas (pp. 165-180). Porto Alegre, RS: Rede Unida.

Mayora, M. (2016). O crack e a rua. In: J. Souza (Org.), Crack e exclusão social (pp. 137-144). Brasília, DF: São Jorge.

Moura Júnior, J. F., \& Ximenes, V. M. (2016). O lugar do uso de drogas na identidade de uma pessoa em situação de rua. Gerais: Revista Interinstitucional de Psicologia, 9(2), 259-276.

Moura Júnior, J. F., Ximenes, V. M., \& Sarriera, J. C. (2013). Práticas de discriminação às pessoas em situação de rua: histórias de vergonha, de humilhação e de violência em Fortaleza, Brasil. Revista de Psicología Universidad de Chile, 22(2), 8-28.

Muyalaert, C. J., Sarubbi Júnior, V., Gallo, P. R., Rolim Neto, M. L., \& Reis, A. O. A. (2014). Entrevistas narrativas: Um importante recurso em pesquisa qualitativa. Revista de Escola de Enfermagem da USP, 48(n. spe 2), 193-199. https://doi.org/10.1590/S0080-623420140000800027

Paiva, F. S., Ferreira, M. L., Martins, M. Z. F, Barros, S. L. C. F., \& Ronzani, T. M. A. (2014). A percepção profissional e comunitária sobre a reinserção social dos usuários de drogas. Psicologia \& Sociedade, 26(3), 696-706. https://doi. org/10.1590/S0102-71822014000300018

Pinheiro, W. N., \& Monteiro, C. F. B. (2016). Moradores de rua e as justificativas de permanência: Uma análise de aspectos psicossociais. Revista Uningá Review, 25(1), 124-130.

Prates, J. C., Prates, F. C., \& Machado, S. M. (2011). Populações em situação de rua: Os processos de exclusão e inclusão precária vivenciados por esse segmento. Temporalis, 11(22), 191-215.

Prestes, T. K. A. (2017). A história do Homo psicoativus: Uma análise arqueogenealógica da redução de danos (Dissertação de Mestrado). Departamento de Psicologia, Universidade Federal do Ceará, Fortaleza, CE, Brasil.

Resolução no 510, de 7 de abril de 2016. O Plenário do Conselho Nacional de Saúde em sua Quinquagésima Nona Reunião Extraordinária, realizada nos dias 06 e 07 de abril de 2016, no uso de suas competências regimentais e atribuições conferidas pela Lei n o 8.080, de 19 de setembro de 1990, pela Lei n o 8.142, de 28 de dezembro de 1990, pelo Decreto n o 5.839, de 11 de julho de 2006... Recuperado de http:/ /bvsms.saude.gov.br/bvs/saudelegis/ cns/2016/res0510_07_04_2016.html 
Rodrigues, J. R. (2017). Identidade, drogas e Saúde Mental: Narrativas de pessoas em situação de rua. (Trabalho de Conclusão de Residência Multiprofissional em Saúde Mental -TCR). Escola de Saúde Pública do Ceará, Fortaleza, CE, Brasil.

Soares, R. G., Silveira, P. S., Martins, L. F., Gomide, H. P., Lopes, T. M., \& Ronzani, T. M. (2011). Distância social dos profissionais de saúde em relação à dependência de substâncias psicoativas. Estudos de Psicologia, 16(1), 91-98.

Vedovatto, S. M. A. In: Santos, L. M. B. (2010). Outras palavras sobre o cuidado de pessoas que usam drogas. (1ª ed. pp. 159-166). Porto Alegre: Conselho Regional de Psicologia do Rio Grande do Sul, Ideograf.

\section{Jéssica Silva Rodrigues}

Psicóloga. Mestranda em Psicologia na Universidade Federal do Ceará, Fortaleza - CE. Brasil. Residente em saúde Mental pelo programa de Residência Integrada em Saúde da Escola de Saúde Pública do Ceará (RIS - ESP/CE). Fortaleza - CE. Brasil.

E-mail: jsrodriguespsi@gmail.com

\section{Aluísio Ferreira de Lima}

Psicólogo com Pós-Doutorado, Doutorado e Mestrado em Psicologia (Psicologia Social) pela Pontifícia Universidade Católica de São Paulo (PUCSP). São Paulo - SP. Brasil. Especialista em Saúde Mental pela Universidade de São Paulo (EEUSP). São Paulo - SP. Brasil. Especialista em Psicologia Clínica pelo Conselho Regional de Psicologia (CRP11). Fortaleza - CE. Brasil. Professor Associado do Departamento de Psicologia da Universidade Federal do Ceará (UFC). Fortaleza - CE. Brasil. Bolsista de Produtividade do CNPq.

E-mail: aluisiolima@hotmail.com

\section{Renata Bessa Holanda}

Psicóloga. Doutoranda e Mestre em Psicologia na Universidade Federal do Ceará. Fortaleza - CE. Brasil. Bolsista CAPES. E-mail: renatabessa_h@hotmail.com

Endereço para envio de correspondência:

Departamento de Psicologia. Av. da Universidade, 2762 - Área II - CH. Fortaleza. Ceará. CEP: 60020-180

Fortaleza-CE. Brasil.

Recebido 21/11/2017

Aprovado 03/05/2018

Received 11/21/2017

Approved 05/03/2018

Recibido $21 / 11 / 2017$

Aceptado 03/05/2018

Como citar: Rodrigues, J. S., Lima, A. F., \& Holanda, R. B. (2018). Identidade, drogas e saúde mental: Narrativas de pessoas em situação derua. Psicologia:Ciênciae Profissão, 38(3), 424-436.https://doi.org/10.1590/1982-37030004912017

How to cite: Rodrigues, J. S., Lima, A. F., \& Holanda, R. B. (2018). Identity, drugs and mental health: Narratives of people living on streets. Psicologia: Ciência e Profissão, 38(3), 424-436. https://doi.org/10.1590/1982-37030004912017

Cómo citar: Rodrigues, J. S., Lima, A. F., \& Holanda, R. B. (2018). Identidad, drogas y salud mental: Narrativas de personas que viven en situación de calle. Psicologia: Ciência e Profissão, 38(3), 424-436. https://doi.org/10.1590/1982-37030004912017 